\title{
College Students With Asthma: The Perfect Storm
}

As health care costs continue to rise, management of chronic diseases such as asthma becomes paramount. A great deal of attention has been focused on asthma management for children and adolescents, ranging from schoolbased programming ${ }^{1,2}$ and community health workers ${ }^{3}$ to shared decision making. ${ }^{4}$ However, the transition to adulthood goes largely unaddressed. It has been noted that college students with asthma face reduced psychological and academic functioning, ${ }^{5}$ reduced social functioning and quality of life, ${ }^{6}$ and increased risk taking and depression ${ }^{7}$ compared with their healthy counterparts. For these reasons, they represent a vulnerable population.

The American Academy of Pediatrics reports that the decade-old consensus statement recommending a smooth pediatric-to-adult transition in care for those with chronic health needs has not been fully implemented in clinical practice. ${ }^{8}$ Moreover, transition guidelines have not even been addressed on college campuses. A representative survey of United States colleges ${ }^{9}$ indicated that fewer than $10 \%$ of student health centers actively reach out to an entering student with a medical history of asthma for an initial appointment, and over $40 \%$ of schools have no formal system for identifying students with chronic illnesses. The schools that do are more likely to be smaller, private schools. Nevertheless, $83 \%$ of student health centers reported that they had the capability to manage asthma on campus.

But can they? In this issue of Respiratory CARE, the ability of college student health centers to manage asthma is questioned. Collins et $\mathrm{al}^{10}$ noted that less than one fourth $(23.5 \%)$ of their sample offer individual action plans, and only about one third (35\%) have emergency action plans, yet most remain satisfied with the asthma services they offer students, with the caveat that affected students largely underutilize their services.

What does this mean for students with asthma entering college for the first time? What about those who will attend a large university, where the chance of being noticed

Dr Levy has disclosed no conflicts of interest.

Correspondence: Marian Levy DrPH RD, School of Public Health, University of Memphis, 230 Robison Hall, Memphis, TN 38152. E-mail: mlevy@memphis.edu.

DOI: $10.4187 /$ respcare.04296 is small? What if the large university is located in a city named as one of the most challenging places to live with asthma, having worse-than-average crude death rates and emergency department visits for asthma? ${ }^{11}$ Furthermore, what if the student health center does not embrace best practices, such as asthma action plans? A perfect storm ensues.

\section{See the Original Study on Page 1085}

Let us consider the options for primary prevention of this perfect storm. First, as Mellinger ${ }^{12}$ suggests for college students with diabetes, the student's clinician could arrange for an introductory meeting at the student health center upon the freshman's arrival on campus. Second, the student health center could develop a registry and conduct a deliberate outreach to incoming students with asthma. Third, the student health center could, as a policy, implement state-of-the-art protocols, such as asthma action plans. Finally, the university could implement a vigorous marketing campaign directed to students with chronic diseases to make them feel welcome and engaged. This might have great appeal to parents seeking a college for their child with asthma.

From a public health standpoint, poor asthma control among college students can have dire consequences on physical, academic, and economic well-being. By implementing national guidelines for transition, mandating established standards of care, and taking a proactive stance, the student health center can be a port in the storm.

\author{
Marian C Levy DrPH RD \\ School of Public Health \\ University of Memphis \\ Memphis, Tennessee
}

\section{REFERENCES}

1. Bruzzese JM, Evans D, Kattan M. School-based asthma programs. J Allergy Clin Immunol 2009;124(2):195-200.

2. Levy M, Heffner B, Stewart T, Beeman. The efficacy of asthma case management in an urban school district in reducing school absences and hospitalizations for asthma. J Sch Health 2006;76(6):320-324.

3. Fox P, Porter PG, Lob SH, Boer JH, Rocha DA, Adelson JW. Improving asthma-related health outcomes among low-income, 


\section{College Students With Asthma: The Perfect Storm}

multiethnic, school-aged children: results of a demonstration project that combined continuous quality improvement and community health worker strategies. Pediatrics 2007;120(4):e902-e911.

4. Fiks AG, Mayne SL, Karavite DJ, Suh A, O'Hara R, Localio AR, et al. Parent-reported outcomes of a shared decision-making portal in asthma: a practice-based RCT. Pediatrics 2015;135(4):e965-e973.

5. Carpentier MY, Mullins LL, Van Pelt JC. Psychological, academic, and work functioning in college students with childhoodonset asthma. J Asthma 2007;44(2):119-124.

6. Fedele DA, Mullins LL, Eddington AR, Ryan JL, Junghans AN, Hullmann SE. Health-related quality of life in college students with and without childhood-onset asthma. J Asthma 2009;46(8):835-840.

7. Bender BG. Risk taking, depression, adherence, and symptom control in adolescents and young adults with asthma. Am J Respir Crit Care Med 2006;173(9):953-957.
8. American Academy of Pediatrics, American Academy of Family Physicians, American College of Physicians, Transitions Clinical Report Authoring Group, Cooley WC, Sagerman PJ. Supporting the health care transition from adolescence to adulthood in the medical home. Pediatrics 2011;128(1):182-200.

9. Lemly DC, Lawlor K, Scherer EA, Kelemen S, Weitzman ER. College health service capacity to support youth with chronic medical conditions. Pediatrics 2014;134(5):885-891.

10. Collins KP, Weiss-Randall DN, Henry NR. Managing asthma on the college campus: findings of a Texas pilot study. Respir Care 2015; 60(8):1085-1090.

11. Asthma and Allergy Foundation. The most challenging places to live with asthma. 2015. www.AsthmaCapitals.com. Accessed May 8, 2015.

12. Mellinger DC. Preparing students with diabetes for life at college. Diabetes Care 2003;26(9):2675-2678. 